\title{
OS CONFLITOS FAMILIARES E A MEDIAÇÃO FAMILIAR NA EUROPA ${ }^{1}$
}

\author{
Virgínia Zambrano
}

\section{RESUMO}

O presente artigo tem por objetivo discutir os conflitos familiares e as técnicas atualmente utilizadas na Europa, mais especificamente na Itália, para desincentiválos na tentativa de preveni-los ou então para tratá-los, quando já instaurados. Para fins de cumprir com tal meta o texto aborda a disponibilidade dos direitos envolvidos na contenda e a possibilidade de que eles sejam tratados pela mediação, debatendo as críticas a tal instrumento. Além disso, o papel do mediador e do juiz também é alvo de investigação. Nestes termos, propõe uma reflexão sobre as estratégias utilizadas atualmente pra resolver os conflitos familiares europeus cujo modelo poderá ser absorvido e aproveitado pelos países da América Latina, dentre eles o Brasil.

Palavras-Chave: Conflito. Família. Jurisdição. Mediação.

\section{LIMITES INTRODUTÓRIOS: AS MÓVEIS FRONTEIRAS DA “DISPONIBILIDADE” DOS DIREITOS}

Quando se discorre sobre mediação familiar e, de maneira genérica, sobre instrumentos de resolução e prevenção dos conflitos, é difícil não deixar-se contagiar pelas reflexões sobre "the reasons of popular dissastisfaction with the administration of justice" pelas quais já, há mais de cem anos, Roscoe Pound convidava a "American Bar Association" a reformar o regime existente. A sempre mais recomendada exigência de diversificação das técnicas de tutela, em relação à necessidade de satisfazer aquela "conflicting idea of justice" sobre a qual discorria Pound, conduziu ao aparecimento de uma série de instrumentos de conflict management, com o objetivo de garantir uma mais eficaz, completa, efetiva tutela dos interesses das partes, de forma concreta ${ }^{3}$. Objetivo este, que não pode negligenciar elementos tais como tempos, modos, com os quais se administra o conflito.

$\mathrm{Na}$ verdade, em alguns casos, a própria natureza do conflito "estimulou" uma fuga em direção a formas do tipo lato sensu mediativas, capazes de assegurar em tempos mais breves e racionais o alcance de uma composição mais satisfatória da lide $^{4}$. De modo que não causa assombro se o progressivo expandir-se da cultura da mediação tenha acabado, com o passar do tempo, por derrubar, recte deslocar, as já móveis fronteiras da "disponibilidade do direito", consentindo o ingresso da conciliação nos âmbitos tradicionalmente reservados à jurisdição ordinária: pensemos - querendo recordar algumas - às controvérsias em matéria de trabalho ou de emprego público, à tutela dos consumidores, ao caso do processo societário, ou ainda, à disposição do art. III - 269, n. 2, letra g do Tratado Constitucional Europeu. ${ }^{5}$. Da mesma forma, é leit motiv, até mesmo bastante conhecido, aquele segundo o qual uma tentativa similar de erosão deva, por via de regra, justificar-se 
em nome da superior exigência de pôr remédio à crise da justiça. Justamente o argumento deflacionista tem, aliás, assumido uma relevância gradualmente preponderante no debate desenvolvido em torno dos instrumentos de conflict management.

E, todavia uma vez abandonado o assegurado plano das finalidades, as certezas argumentativas cedem diante da dificuldade de reconduzir ao sistema a figura da conciliação-mediação ${ }^{6}$. A discórdia, na espécie, investe não só na questão da mediação como instrumento obrigatório ou facultativo ou da sua qualificação jurídica (se condição de proponibilidade ou de procedimentabilidade da ação em juízo), mas o próprio perfil subjetivo, sendo dúbios, quais sejam no momento oportuno, os sujeitos casualmente predeterminados. Aspectos estes, que se perdem todos entre as pregas de disciplinas, quanto mais heterogêneas e diversificadas ${ }^{7}$. É como dizer, em outros termos, que incerto se revela o an, o quomodo, o quando e quivis.

Nem a mediação familiar escapa de similares interrogações, não obstante o seu (im)por-se como meio para garantir, em caso de divórcio, a recuperação na chave funcionalista das relações familiares. Então, é fácil observar como justamente estes contra-impulsos dogmáticos sobre os quais se discute coloquem em crise até mesmo a sistematização da mediação no ordenamento. De fato, se é a escassa atração da justiça tradicional a oferecer uma explicação válida para compreender, ao menos em parte, o desenvolvimento de percursos alternativos, então é a própria questão da sistematização de tais formas de conciliação/mediação, a ser advertida pelo operador do direito em favor destas razões do coração, que na família são mais do que nunca evidentes.

Cada vez mais, pois, a tendência à assistematização é quase uma íntima motivação, um elemento congênito que, em modo mais ou menos latente, anima estas técnicas; a recondução ao sistema, que aqui significa inserção e integração no processo, é, de fato, percebida como um risco de atração à ineficiência dele mesmo". Au contraire como a doutrina não deixa de salientar, "as conciliações extrajudiciais, por serem boas, exigem uma administração da justiça eficiente". Sem levar em consideração, como demonstra a experiência das ADRs mediativas, de acordo com a distinção a elas feita pela doutrina americana, que estas formas podem no momento operar como alternativa válida à justiça decisória, enquanto têm se afirmado em plena autonomia e independência com relação ao processo ${ }^{9}$. O que equivale então a dizer, que Mediação e Conciliação, se colocam mais corretamente em relação de acessoriedade (já não de alternatividade) a respeito da justiça de fonte estatal, cuja dificuldade não faz mais do que parecer instrumental o recurso a tais remédios alternativos.

Ex altera parte, no entanto, é justamente uma condição semelhante de subordinação que concorre para agravar a falta de nitidez que geralmente acompanha a definição de tais institutos, e que o próprio código civil não soube dissolver nem mesmo nos tímidos reconhecimentos expressos pelos arts. 155 sexies c.c. e 342 bis c. c $^{10}$. De forma que somente a salvação da figura parece, rebus sic stantibus, confiada a sua não obrigatoriedade, a qual lhe impede aquele típico enrijecimento da experiência anglo-saxônica, onde precisamente a mediação parece, ao contrário, quase perder o seu significado de justice without law ${ }^{11}$ e deixar aquela função de "re-eorient the parties towards each other, not by imposing rules on 
them, but by helping them to achieve a new and shared perception of their relationship, a perception that will redirect their attitudes and dispositions toward one another" ${ }^{12}$.

Não indo além, esta insuficiência das respostas denuncia a excessiva simplificação do debate sobre as formas de ADR, que parece permanecer prisioneiro do "fascínio" exercido por um ideal de justiça informal ou de better justice ${ }^{13}$. Dúvidas e perplexidades às quais, evidentemente, nem mesmo a Mediação em geral, e aquela familiar em particular, se subtraem ${ }^{14}$.

\section{A MEDIAÇÃO COMO ALTERNATIVA À JURISDIÇÃO ORDINÁRIA: CRÍTICA DA TESE}

Como se observou, no caso da Mediação familiar, a pesquisa que se limitasse a individuar na insatisfação frente ao método jurisdicional a razão da sua afirmação, seria sem dúvida criticável.

Essa, de fato, não faria mais do que substituir pela causa aquele que, ao invés, é somente um efeito. Considerar, em outros termos, que a Mediação tenha se afirmado exclusivamente em consideração da escassa flexibilidade do sistema tradicional e, além disso, para remediar a excessiva rigidez das regras, incapazes de adaptar-se às delicadas repercussões também psicológicas do divórcio, não está distante de uma atitude de celebração, que à pergunta sobre o porquê da Mediação responde tautologicamente, individuando na personalização da solução, no favorecer o diálogo entre as partes, na tutela dos menores, as razões que a fazem preferível ao processo ordinário ${ }^{15}$. 0 que, evidentemente, não é ou, ao menos, não Ihe exaure as implicações. É bem verdade que a premissa não explicitada na Mediação reside na retórica ${ }^{16}$ relacionalidade-responsabilidade que esta aclama, assim como na atenção ao perfil emocional da relação, que supera os limites das condições de relevância do fato que condicionam o raciocínio do juiz.

Raramente, porém, discorrendo de Mediação, se tomam as distâncias de uma atitude auto-referencial. Ora, não resta dúvida que a tendência a privilegiar soluções de controvérsias negociadas se impõe - e não só no âmbito familiar - ao testemunho de um difundir-se da cultura da negociação, para a qual a crise da justiça sem dúvida contribui. Resulta, porém de cristalina evidência, como o desenvolvimento de novos instrumentos de composição seja o resultado do afirmarse de uma diversa concepção do direito em relação ao estruturar-se dos sistemas sociais.

A complexidade do ambiente social e econômico funciona como contexto de referência para definir o modo no qual se ativam mecanismos em grau de selecionar, entre múltiplas expectativas, aquela que será, pois, destinada a prevalecer. $\mathrm{O}$ aumento das expectativas individuais não normatizadas põe assim as premissas para a abertura a um contencioso do qual depende o processo de seleção/individualização daquela expectativa que a irá consolidar-se no direito. 0 formalismo que caracteriza o procedimento e garante a previsibilidade do resultado e uniformidade dos critérios, é então percebido como uma espécie de mal necessário, aceitado - rectius tolerado - porque satisfaz precisas exigências de certeza jurídica $^{17}$. Neste contexto, o modelo negociado oferece resposta às exigências de 
uma diversificação social que, superando o paradigma do formalismo e da modernidade, desenvolve uma aproximação alternativa e mais flexível ao conflito ${ }^{18}$. Entretanto, a maior flexibilidade e personalização das decisões não impedem que à justiça estatal continue a ser reservado um espaço privilegiado em consideração de uma superioridade da resposta institucional que se liga àquele efeito de certeza $e$ segurança do qual se falava ${ }^{19}$.

\section{A DIFÍCIL RECONDUÇÃO AO SISTEMA DO INSTITUTO}

Emblemático, nesse sentido, é como, na generalidade das experiências jurídicas, os institutos da separação e do divórcio evoquem todas as dificuldades relativas à dinâmica do processo civil: duração do procedimento, custos, conflitos entre as partes, individuação da pessoa responsável pela separação, medidas a assumir em sede provisória ou cautelar. Em cenário semelhante, a Mediação se apresenta, assim, como a elaboração de um conflito a serviço de um sujeito terceiro e imparcial que, em um contexto autônomo com relação ao procedimento judiciário, tende a garantir alguma (re)organização das relações ${ }^{20}$. Apesar da estrutura polissemântica que a expressão possui, as definições que se redescobrem até mesmo em contextos de ordenamentos diversos, sublinham esta característica, reforçando a maneira como a Mediação, diferentemente do processo, supere o conflito através da sua "gestão", gerando um efeito deflacionista a longo prazo, sem sacrificar a especificidade dos interesses das partes.

A conclusão supera o momento, por assim dizer, familiar stricto sensu, como è comprovado pelo mesmo dado positivo que transcorre, desde a crise entre genitores (art. 155 sexies c.c) ${ }^{21}$, à violência interna do casal (art. 342 bis c.c), até as controvérsias essenciais referentes à definição inter vivos das relações de sucessão (art. 768 bis c.c) ${ }^{22}$, além daquela do art. 342 ter c.c. ${ }^{23}$ E assim, sob o denominador comum das alternativas dispute resolution (ADR) se resumem uma pluralidade de casos concretos diferentes, a respeito dos quais conciliação, julgamento, perícia e arbitragem funcionam como termos de confronto aos quais recorrer, em via analógica, ou evitar, em sentido contrário. Sob o primeiro perfil (aquele, de fato, da identidade funcional) é impossível não revelar-se como a autonomia e a imparcialidade devam conotar tanto a atividade do mediador, quanto por exemplo aquela do árbitro ou do perito.

Sob o segundo perfil, (aquele, por assim dizer, da "enucleação das diferenças') é inegável como a mediação coloque alguns problemas de definição da relação entre juiz e Mediador que não recorre em quaisquer dos casos concretos citados $^{24}$. Trata-se, na verdade, de uma questão a tal ponto delicada, que não encontra solução homogênea dentro da mesma área do Civil Law, na qual, espera a dinâmica do processo civil, o juiz normalmente se vale ou pode valer-se de auxiliares e consultores técnicos.

Mas procedamos com ordem e se justifique, então, 0 recurso às classificações mesmo que seja ao limitado fim de uma maior clareza e simplificação do discurso. Punctum dolens do debate em torno da mediação é, precisamente, aquele que concerne à escassa atenção normalmente prestada à previsão de um orgânico percurso formativo do mediador, diversamente de quanto acontece para outros técnicos do procedimento. Na maioria das vezes é deixada no vago, de fato, 
seja a definição das competências profissionais, seja 0 quadro das responsabilidades. Se colocarmos à parte a experiência espanhola que, mesmo na variedade de soluções oferecidas pelos singulares Derechos Forales, se preocupa em estabelecer um específico percurso formativo (com a requisição de um apropriado título de estudo), os outros ordenamentos europeus não se mostram igualmente pontuais.

Permanece imprecisa, seja a questão relativa ao título de estudo, indispensável para ascender aos cursos de formação, seja - precisamente - 0 inter necessário para exercitar este tipo de atividade ${ }^{25}$. Tal insatisfação investe o próprio ordenamento inglês, onde justamente se esperava um diferente sucesso por parte da institucionalização da mediação e onde, ao contrário, somente as iniciativas formativas finalizadas à criação das figuras profissionais foram empreendidas pela Solicitors Family Law Association (SFLA) - em concordância com a Law Society.

No ordenamento italiano a obrigação, para todos os participantes da SIMeF, de subscrever o Código deontológico, não é fonte de adequada garantia para as partes. 0 código, mesmo prevendo uma série de obrigações, algumas de conteúdo positivo, outras negativo, não é em grau de garantir qualquer exatidão metodológica, nem de fixar linhas precisas de conduta, com a conseqüência de levantar, sob o perfil da responsabilidade, a interrogação sobre as regras a aplicar na hipótese de dano ${ }^{26}$.

\section{A RELAÇÃO ENTRE O MEDIADOR E O JUIZ: A EXPERIÊNCIA FRANCESA E ESPANHOLA}

A questão, na realidade, é de fôlego mais amplo, a partir do momento em que une as duas extremidades e pressupõe em si o correto enquadramento do segundo dos dois reclamantes, aquele, vale dizer, da relação entre o mediador e o juiz, e a partir do momento em que este último possa proficuamente reenviar as partes ao primeiro. A complexidade do fato - fazíamos alusão a isto - emerge com clareza da comparação entre as diversas experiências da França, Itália, Inglaterra e Alemanha ${ }^{27}$.

A primeira, em particular, encontra a principal referência normativa no art. 21 NCPC (Nouveau Code de Procedure Civile) que atribui ao Juge aux affaires familiales (JAF) poderes de conciliação tais da tornar igualmente incertos os contornos entre a função da mediação e conciliação. A Loi n. 2002-305 du 4 mars 2002 relativa à l'autorité parentale, não dissipa, por outro lado, as dúvidas: mesmo que de fato atribua ao juiz o poder de conciliar ou intimar às partes que encontrem um mediador, na realidade não atribui relevância autônoma para a figura da mediação ${ }^{28}$. Esta se desenrola além de iussu iudicis, sob o controle da autoridade judicante à qual o Mediador, diversamente do que acontece na Bégica, é forçado a reportar-se. A Mediação parece assim configurar-se, exceto em algumas experiências jurídicas - como na Bélgica ${ }^{29} \mathrm{e}$, precisamente na Espanha - como uma espécie de subprocedimento, controlado à distância pelos tribunais. Neste contexto, o mesmo consenso manifestado por parte dos cônjuges à mediação, não parece muito diferente de uma mera autorização, que absolve a função de eliminar um obstáculo ao desenvolvimento de um procedimento, por outro lado, já bem definido. 
A dificuldade de aceitar no seu interior novos modelos de composição confirma, para o sistema processual, em outros termos, uma substancial "resistência" do modelo tradicional em acolher no seu interior "outros" instrumentos de gestão dos conflitos ${ }^{30}$. O debate que, na experiência italiana, se desenvolveu em torno da natureza jurídica do mediador, demonstra a dificuldade de não comprometer aquela autonomia e imparcialidade que tanto a Racc (98) 1 quanto o art. 13 da Convenzione Europea dos direitos do homem consignam a esta atividade. O problema nem investe exclusivamente o ordenamento italiano, a partir do momento em que a institucionalização da Mediação - pensemos à experiência inglesa ou espanhola - mesmo dando espaço à figura do mediador, não resolve a questão da sua autônoma configuração dentro do processo.

Sob o fundo paira a sombra da dimensão psicológica do instituto, que arrisca comprometer a exegese jurídica até desembocar, em alguns casos, em verdadeiro e real desinteresse. A situação se modificou só aparentemente em consequência da Lei 54/2006 que, no introduzir a guarda compartilhada, destranca as portas a este instituto (conforme novo art. 155 - sexies, $2^{\circ}$ parágrafo c.c.). Diferentemente do previsto em alguns desenhos de lei, o legislador italiano se orientou no sentido de uma absorção da Mediação no processo, transformando o papel do mediador familiar naquele de um simples auxiliar do juiz ${ }^{31}$.

A Mediação se torna então uma fase eventual do procedimento, com a consequência de considerar os especialistas do art. 155 sexies, parágrafo $2^{\circ}$, c.c. meros "auxiliares do juiz" - que então não se distinguiriam das figuras do art. 68 c.p.c. - aos quais precisamente $o$ juiz pode fazer referência a cada necessidade e para informar, mediante relação, os resultados da mediação ${ }^{32}$. A ausência de normas processuais específicas que se preocupem em dar adequada sistematização à Mediação, assim como a falta de previsão de um determinado percurso formativo deixam, porém indefinidos, aspectos cuja definição é essencial aos fins do concreto funcionamento da previsão do art. 155 sexies, parágrafo 2 c.c. Se delineia assim um quadro extremamente lacunoso, cujas linhas de guia traçadas pela Associazione Nazionale Magistrati (Associazione che riunisce tutti i giudici italiani) tentam, em parte, remediar. Em outro sentido, pois, o protesto operado à Mediação do art. 13 da Convenzione Europea dos direitos do homem consente excluir que essa opere como uma condição de proponibilidade da questão. Por outro lado, não parece que seja possível - considerada a função da Mediação - frear a sua obrigatoriedade, que acabaria por violar o direito de acesso à justiça ${ }^{33}$. Nem o seu caráter voluntário é colocado em discussão, pela condição de que, para o reenvio ao Mediador se deva esperar pela iniciativa do juiz. Deste ponto de vista, as soluções, no panorama europeu se mostram bastante heterogêneas, como declara a exigência (mas também da dificuldade) de atrair, de qualquer maneira, a mediação ao processo ${ }^{34}$.

Neste sentido é clara, por exemplo, a escolha da Lei Catalã, que regula tanto a Mediação sob iniciativa do juiz - e então gratuita - como aquela requerida pelas partes, enquanto não se ocupa da mediação negociada em um contexto privativo. Enquanto ao invés se mostram, com mais amplo fôlego, as previsões contidas nas leis das outras Comunidades Autônomas, que abrem a todos os tipos de mediação, sejam eles convencionais ou extrajudiciais, ou seja, intrajudiciais, enquanto aviadas sob provimento do juiz no curso de um procedimento que é suspenso ${ }^{35}$. Em alguns 
Tribunais italianos, a ausência de uma normativa específica foi desenvolvendo-se como uma práxis, em certos aspectos, intermediária. Ao caráter voluntário se associava a circunstância de que na Mediação, as partes podiam dirigir-se, sempre no caso de não existirem obstáculos particulares, exclusivamente invito iudicis, considerado o único legitimado a propô-la ${ }^{36}$.

Uma melhor adaptabilidade do instrumento em exame se adverte, ao contrário, naqueles ordenamentos nos quais a dinâmica processual é ligada a um sistema de tipo adversary ${ }^{37}$. Na Inglaterra, por exemplo, a possibilidade de recurso à "mediation", em vez de à 'litigation", nas situações de crise familiar, é ofertada pela Family Law Act, que, no procedimentalizar o percurso que conduz ao divórcio, revalida sobre base voluntarística o papel das partes. Sai assim reforçado, a nível sistemático, um quadro normativo que vê no recurso ao juiz um remédio extremo. Nesse sentido depõe a adoção, seja de um código de procedimento unificado (pensemos ao Access to Justice Act 1999), seja de um "pre-action protocol", que estabelece preventivamente tempos e fases do caso. $O$ juiz, de sua parte, tem 0 poder de ordenar, em qualquer estado e grau do processo, que o casal participe de um encontro a tal fim mirado. O colóquio se desenrola de fato, porém, sob o seu controle direto, cabendo também à autoridade judiciária o poder de requerer, ao encarregado, uma relação final detalhada com relação à atividade desenvolvida, às decisões adotadas, ao comportamento tido pelas partes, etc ${ }^{38}$.

A autonomia das partes de qualquer modo não é absoluta, como demonstra o fato de que qualquer acordo alcançado pelos separandos na "fase de reflexão" deve ser submetido à homologação da autoridade judiciária. Embora a formulação do Séc. 29 do FLA tenha feito surgir não poucas dúvidas interpretativas, também o sistema inglês parece abrir à "voluntariedade" da mediação".

Na verdade, neste ordenamento, a maior parte das críticas e das resistências à "normatização" da Family Mediation veio dos advogados, que acreditaram que a Mediação como instrumento de colaboração entre figuras de profissionais especialistas diferentes, acabasse operando em prejuízo do papel que eles foram chamados a desenvolver ${ }^{39}$. Em grande parte para silenciá-la, pela inexistência de normas unitárias de conduta e standard únicos capazes de assegurar um nível elevado de qualificação profissional. Problema este, nem novo, nem de solução ágil e que, longe de acometer somente o ordenamento inglês, é objeto de vivaz debate também em outros sistemas jurídicos, tornando indeferível uma intervenção específica do legislador, destinada a definir obrigações e deveres de conduta do mediador $^{40}$.

Neste contexto, um discurso diferente deve, ao contrário, fazer-se pela experiência espanhola que, mesmo na diversidade das soluções adotadas - mas sempre em linha com os princípios contemplados nas leis forenses em tema de direito de família Catalogna lei 1/2001, Galizia (Lei n. 3/1997 de 9 de junho) além de Valenza, Castilla y Leòn, la Mancha - se qualifica por uma marcada opção em direção ao modelo mediativo, conforme testemunhado pela circunstância em que o legislador põe claramente, mediação e procedimento jurídico, não em relação de alternatividade entre eles, mas sim de verdadeira e própria complementariedade. 
A diversidade de soluções se explica, de resto, em consideração da variada margem que cada Derecho Foral reserva à autonomia das partes e à negociação ${ }^{41}$. A Mediação entra assim no circuito da gestão da crise familiar tout court (e é aplicável, portanto à pareja de hecho), enquanto instrumento em grau de encontrar aplicação para a definição seja de perfis pessoais, como patrimoniais. Para que não se prejudique a autonomia do mediador, já que, diversamente do que se verifica em outros ordenamentos, os encargos de designação e controle (normalmente desenvolvidos pelo juiz) são confiados ao Centro de Mediación Familiar (ente privado de personalidade jurídica própria e que depende do Departamento de Justiça), que desenvolve funções de importante relevo prático, como a manutenção do Registro dos mediadores, a designação dos mesmos e o controle de suas operações. O chamado aos princípios da voluntariedade - em acolhimento ao princípio dispositivo - além da confidencialidade, sob tutela da privacy, e da imparcialidade, evidencia o caráter negocial da mediação, caráter que encontra uma confirmação ulterior na definição das obrigações que oprimem o mediador e a cujo descumprimento eles são chamados a responder ${ }^{42}$. Do ponto de vista processual, pois, esta pode ter lugar tanto antes do início de qualquer iniciativa judiciária, quanto, em pendência desta, se for o caso, o requerimento de suspensão pode ser conjunto, ou mesmo se vindo de uma só parte, ser aceito pela outra. De acordo com a fase em que se efetua, a Mediação assume assim, uma função diversa. Em casos nos quais ela intervém sobre o conflito, ou seja, em uma fase na qual o juiz não tenha ainda sido investido pela controvérsia, a sucessiva homologação do acordo, por parte da autoridade judiciária, vale a atribuir relevância jurídica ao mesmo. Claro que o regime de responsabilidade, na hipótese de descumprimento, acaba dependendo da maior, ou menor vinculatividade assumida pelo acordo.

\section{A NÃO UNÍVOCA NOÇÃO DE “ALTERNATIVIDADE”}

As dificuldades exegéticas são, na realidade, acentuadas pela reflexão de que na Europa, diversamente do que aconteceu nos Estados Unidos, o desenvolvimento de modelos de informal justice, por razões que devem ser individualizadas na particularidade do sistema processual e na dificuldade de reconhecer uma pluralidade de centros de administração da justiça, não parece conhecer aqueles espaços que ao invés caracterizam o sistema estadunidense. Exceção feita à arbitragem, a atividade de conciliação-mediação parece bastante relegada à margem de um sistema que reconhece outras figuras enquanto elas se desenvolvem especificamente em relação a setores particulares da vida civi $^{43}$. Verdade é que o desenvolvimento dos modelos alternativos de resolução das controvérsias consente em realizar formas de tutela que, com respeito ao modelo tradicional, são mais flexíveis pelo fato de estarem em grau de articular uma resposta que tenha realmente conta dos interesses das partes. Tanto é verdade, que a função atribuída à arbitragem, mediação, conciliação, que justamente operam sempre nos espaços deixados pela justiça “oficial", varia de ordenamento para ordenamento.

A coligação que tradicionalmente se costuma instaurar entre recursos a similares instrumentos alternativos e soluções dos tradicionais problemas como garantia do sistema processual, nem sempre é correta ${ }^{44}$. A mesma função deflacionária, normalmente atribuída em prestígio das técnicas alternativas, pressupõe um tempestivo recurso às mesmas, sanção pela ineficácia do remédio. Por isto, pois, não se deve esquecer que, quase contraditoriamente, os métodos de 
resolução das controvérsias dependem, porém, sempre da estrutura do processo, com a conseqüência de que não é possível apreciar a incidência de técnicas alternativas separadamente do contexto mais geral no qual vão se organizar.

A partir daí a ulterior conquista do fato, pelo qual o mesmo conceito de "alternatividade" arrisca de ressoar ambíguo, e não só, ou não tanto, pela ausência muitas vezes de um pressuposto de caráter substancial (vale dizer a condição de paridade das partes no exercício da atividade de negociação), quanto pelo dúplice significado que a ele se pode geralmente atribuir" ${ }^{45}$. "Alternatividade", de fato, é termo que se refere, indistintamente, seja a formas de regulamento, que se substituem àquele tradicional - como acontece na Austrália, onde à mediação se faz recurso em via principal - seja a modalidades processuais. Tais formas, intervindo dentro do processo, favorecem a conquista de uma solução negociada e se colocam mais seguidamente em relação de "complementariedade", em vez de alternatividade, com o procedimento judiciário.

Daí, também, o alívio de subtrair à mediação a rigidez da conclusão, se é verdade que essa responde a uma lógica diferente e, sobretudo é destinada a incidir sobre direitos subtraídos à disponibilidade das partes. Semelhante natureza, de fato, restitui ao Estado alguma forma de controle, salvando ao mesmo tempo o juiz do embaraço de "administrar" e regular uma realidade, aquela familiar, que mal se concilia com os formalismos do sistema processual. De modo que, a bem ver, o problema diz respeito mais frequentemente à difícil conciliabilidade do sistema processual "continental", e italiano em particular, com a informalidade e velocidade do instrumento. Questão certamente não nova, mas nunca resolvida, que sempre mais faz emergir diferenças substanciais com aqueles ordenamentos - pensemos na experiência americana - que não parecem manifestar nem problemáticas de excessiva carga para as cortes, nem aliviar interrogações específicas com relação ao all'an, ao quando e ao quomodo da mediação, sobretudo, na verdade, graças à fase pré-trialque substancialmente falta ao processo continental.

Ali, ao contrário, o acesso à justiça é geralmente percebido como necessidade de distanciamento de um modelo tradicional, o qual se considera que ofereça resposta pouco satisfatória, especialmente em relação a questões que envolvam tutela dos filhos, confiança e, mais em geral, os aspectos patrimoniais do divórcio. A mediação, em tal sentido, se apresenta, além do que não consiga fazer a conciliação, como válida alternativa ao processo, útil a descongestionar a crise familiar. Podem parecer irreais as expectativas que nela se colocam, sempre mais quando é invocada como modelo para substituir os serviços de assistência legal ${ }^{46}$.

E irreais se revelam nos fatos as expectativas, quando se prescinda da consideração dos pressupostos do instituto, fortemente condicionados pela eficácia do concreto comportar-se de um sistema divorcial, no qual a culpa - também quando desaparece por completo, como aconteceu na França ou na Espanha - acaba por assemelhar-se à fênix cantada por Heródoto que morre, mas morrendo se renova ${ }^{47}$. De fato, fora de um contexto relacional não conflitual, a Mediação perde o seu papel de modelo competitivo, enquanto, por outro lado, o conflito simplesmente por si só não a legitima, em ocorrendo o recurso. Além disso, reclama o in dem placitum das partes, exige o reconhecimento no comando dele, de um mesmo poder negocial e de determinado número de informações suscetíveis de troca. Trata-se, na verdade, 
de elementos intimamente ligados entre si e dotados, cada um deles, de uma própria autonomia funcional e conceitual, que se manifesta no suceder-se das fases que conduzem ao "produto final". Considerados, ao contrário, na sua individualidade, cada um deles conserva uma própria valência exclusiva. Pensemos no acordo, por exemplo, que nada diz sobre a assimetria das partes e pelo contrário, não raramente, representa o ponto de êxito de tratativas extenuantes, que rompem a resistência da parte ou tiram vantagem da posição menos forte que ela exprime ${ }^{48}$. Nestes casos, é desviante imaginar que a sua obtenção esteja efetivamente em grau de satisfazer o interesse das partes, que "are told they are being empowered, but in fact are being forced to acquisce in their own oppression" ${ }^{49}$. Se for verdade, de fato, que o acordo fecha a controvérsia entre os cônjuges, é também verdade que, no tema de relações familiares, o que conta também é o modo pelo qual a ele se chega $^{50}$.

De resto, uma das principais críticas movidas no confronto da mediação, a fim de sublinhar-Ihe a intrínseca fraqueza, é justamente com relação a sua incapacidade de corrigir as relações de força entre as partes. Nem as perplexidades cessam aqui. Se for verdade, como ensina Hart, que ocorre distinguir entre jogos com regras de pontuação e jogos com arbitragem de marcação de pontos, para demonstrar como o nível de previsibilidade da decisão influencie a escolha do modelo decisório, então bem poderia a mediação qualificar-se como uma partida sem árbitro e sem pontuação. Quem decide sobrepor-se a ela, em outros termos, aceita jogar uma "partida" sem as regras, as formalidades que atribuem certeza e objetividade à decisão. A mediação se torna, então, uma real alternativa ao procedimento judiciário, somente se as partes conseguem, através do acordo, obter uma vantagem que o dispositivo do juiz não consentiria, de maneira nenhuma, alcançar.

\section{A GESTÃo CONTRATUAL DA CRISE FAMILIAR: LIMITES E PROSPECTIVAS}

Duvidoso é, ao invés, se o constante chamado ao consenso das partes introduza uma reconstrução em termos contratuais do instituto, de acordo com o que, a partir dos anos noventa, sugere o movimento de Collaborative Law, desenvolvido no Canadá e nos Estados Unidos ${ }^{51}$. A gestão contratual da crise familiar passa, na espécie, através da "mediação" de um advogado que, valendo-se da própria experiência, direciona as partes, conscientes dos aspectos jurídicos secundários e não evidentes do conflito, frente a um acordo. As relações familiares transcorrem assim decididamente em direção à área dos compromissos negociais, segundo um mecanismo de automediação dos separation agreements não realmente desconhecido, justamente, à experiência inglesa ${ }^{52}$.

0 documento que contém as estatuições, no que diz respeito às consequências pessoais e patrimoniais do divórcio, longe de ser o produto final de uma decisão meramente concordada (como acontece a propósito da mediação) é mais o êxito de uma tratativa que põe remédio àquela condição de power imbalance pela qual é, ao invés, afetada a mediação. $O$ documento final (no qual conflui 0 acordo) particularmente, mesmo não perdendo as características da negociação, abandona a aparência tradicional de mero bargaining, por apresentar-se mais como produto de a multi-issue strategy, ou seja, como instrumento em grau de afrontar, sob um plano complexo e geral, questões relativas à guarda da prole, exercício de 
direito de visita, prestações alimentares, divisão do patrimônio comum e assim por diante.

E é exatamente uma natureza semelhante que, colocando o Droit Familial Collaborative (ou Collaborative Family Law) na metade do caminho entre a mediação e a negociação tout court, torna preferível este novo modelo de gestão do conflito, que chega a assinalar, pelos evidentes acentos contratuais, o próprio insucesso da Mediação. Nem a conclusões diversas é dado chegar através da leitura da Charte collaborative francesa, por meio da qual as partes se empenham, por toda a duração do processo de negociação, a não recorrer ao juiz, a comportarse segundo a boa-fé e, sobretudo a comunicarem-se todas as informações necessárias à gestão do divórcio ${ }^{53}$. A contratualização da gestão da crise familiar se torna assim, sintoma de uma superação definitiva das lógicas solidarísticas, à total vantagem de um 'fight on equal ground" que pressupõe, ex adverso, o respeito a um princípio de igualdade.

De resto, nesta nova época da negocialidade que parece caracterizar o direito de família, o reclamo (quase constante) à categoria do contrato, não somente não surpreende, mas quase se impõe. O próprio ordenamento italiano, mesmo sensível às solicitações derivadas da categoria do negócio jurídico, não renuncia a uma acentuação dos perfis da bilateralidade e da patrimonialidade na definição das temáticas familiares. $\mathrm{E}$ o pensamento ocorre não somente aos tradicionais reclamos do art. 160 c.c ou, por outro lado aos arts. 159 e seguintes c.c. quanto, em particular, aos arts. 155 e seguintes c.c. nos quais o definitivo ingresso da lógica negocial nas relações familiares é ritmado pela repetição do chamado ao acordo pela definição de aspectos pessoais, assim como econômicos ${ }^{54}$.

De resto, a emersão de métodos alternativos de resolução das controvérsias e da mediação, em particular, enquanto embasada sobre uma diferente concepção da mesma função reguladora do direito, é originada sob muitos aspectos, exatamente pelo multiplicar-se da realidade familiar. Sem percorrer novamente o declive das reflexões que, exaurindo-se na declinação ao plural do tema "família", não se distanciam de uma mera constatação do existente, o dado significativo que o diversificar-se dos modelos sociais desvela, é no papel desenvolvido pela autonomia privada. A evolução do direito de família segue, neste sentido, uma evolução social que, recuperando a singularidade da experiência humana, faz da liberdade individual a verdadeira protagonista da diversificação das estruturas familiares ${ }^{55}$.

De modo que o problema torna-se, no caso, aquele de verificar se o esquema do contrato seja efetivamente funcional às exigências de tutela de singulares posições jurídicas. Ao silêncio do legislador italiano, malgrado a traços rompidos por reconhecimentos mais ou menos explícitos (pensemos, precisamente, no recente art. 155 c.c.), faz eco a atitude, por assim dizer, "previsível" daquele francês, intentado a esconder-se atrás do reconfortante e, todavia, insatisfatório chamado às notáveis categorias dos direitos disponíveis e indisponíveis, para distinguir os acordos imediatamente vinculantes daqueles que, ao invés, são submetidos à necessária homologação do juiz (conforme art. 230 e 373-2-7 do Código Civil). A finalidade não declarada, além da dúbia tendência a distinguir neste âmbito os direitos de acordo com a sua natureza, disponíveis ou menos, é aquela de conciliar a exigência de deixar as partes livres para definir todos os aspectos do divórcio, com 
a necessidade de garantir o controle do juiz ${ }^{56}$. Quando a exigência de deixar as partes livres para alcançar um acordo que defina todos os aspectos do divórcio se substancia na inserção, no contrato de cláusulas, por meio das quais as partes se empenham a não recorrer ao juiz. Nesta perspectiva o "engagement à ne pas recourir au juge"(i cd "disqualification agreements") opera como verdadeiro e próprio mecanismo de incentivo para alcançar o acordo, sem que na presença desta cláusula o temor daquele going to court possa condicionar, de algum modo, os êxitos da negociação.

O Droit Familial Collaborative, abrindo-se definitivamente à lógica do contrato, recupera então aquela espécie de ambigüidade estrutural que caracteriza, pelo contrário, a Mediação, individuando-lhe também a sua fraqueza, vale dizer a sua pretensão, a satisfazer direitos e então, posições subjetivas fortes, através do recurso a técnicas de composição que se distanciam da dimensão jurídica do conflito $^{57}$.

Verdadeiramente - a respeito do Droit Familial Collaborative ou do seu homólogo americano, o Collaborative Family Law - a mediação segue percursos mais acidentais, no momento em que o mesmo reenvio à regra contratual se choca com as não irrelevantes dificuldades acima evidenciadas. Que, por outro lado, semelhante avaliação deva necessariamente conduzir a uma "posposição" do instituto a respeito de outras, e mais válidas, formas negociais, é silogismo talvez não totalmente justificado. De fato parece responder mais a uma leitura da figura em chave destacadamente subjetiva, sendo inegável como a mediação inclua, de qualquer modo em si, a evidente vantagem de garantir uma ética de responsabilidade, na irretroatividade da relação genitorial, com relação ao dissolverse do vínculo conjugal, evitando o risco de respostas impessoais fornecidas por um terceiro sujeito, precisamente o juiz. É também verdade, porém que se em abstrato a mediação, mais do que a conciliação, se candidata, em teoria, como válida alternativa ao processo, contribuindo efetivamente, em quaisquer circunstâncias, a descongestionar a crise familiar, na prática aparecem irrealistas as expectativas que nela se repõem.

No entanto, restam irresolvidas (como se viu), toda uma série de problemas, de não secundária importância: a natureza jurídica do acordo, a sua enforceability, a relação com o procedimento judiciário, o caráter e a função do mediador e assim por diante $^{58}$. 0 que leva uma casta de juristas, todavia instruídos à litigation, diante da não permissão à voz ativa, a retirarem-se sob o mais modesto papel de consultores.

\section{CONCLUSÕES}

Quais, então, as possíveis conclusões? Não existe dúvida que, ao menos no sistema italiano, a ausência de uma ordem normativa precisa tenha contribuído para ignorar as expectativas daqueles que consideravam poder saudar a mediação como uma válida alternativa à jurisdição ordinária na definição da crise da família. Em geral, se é inegável então que a falta de profissionalização específica (como aquela dos mediadores, precisamente) contribuiu (e contribui) muito para incidir sobre a correta eficácia do instituto, é também verdade que os sinais de "crise", ou quanto menos de perda do real significado da mediação, provém exatamente das mesmas 
realidades normativas - USA e Inglaterra - nas quais o instituto surgiu e se impôs com maior incisividade. As causas da decadência são provavelmente pesquisáveis naquele processo de redefinição do papel do juiz, que abandona as vestes decisórias, para assumir o semblante de um "case manager", sempre mais preocupado com a projeção futura e com o impacto que ela terá sobre os cônjuges e sua prole. A tendência é evidente, sobretudo nos USA, onde a atenção ao interesse do menor possui um valor didático que não raramente se exprime na elaboração de verdadeiros e precisos mandatory parent education programs ${ }^{59}$.

Também quando não se chega a tais resultados, a exigência de controlar o respeito aos acordos, o exercício do direito de visita, a prestação alimentar, deu origem a soluções nas quais o recurso a técnicas não adversary, nem punitivas pretende garantir o cumprimento dos compromissos assumidos, estimulando um clima de cooperação entre as partes. As cortes terminaram assim, predispondo uma série de serviços acessórios e de consultoria, com o objetivo de dar vida a um sistema mais eficiente e mais "family friendly" 60. Deste panorama sai modificada a própria atividade do advogado, que tende sempre mais a colocar lado a lado melhor - a substituir a atividade de representação dos interesses da parte, por aquela de mera consultoria. E, todavia, precisamente a atração da Mediação pelo processo acaba por perder as peculiaridades, a dissolver-lhe os traços distintivos ao ponto tornar difícil, se não impossível às vezes, distingui-la de qualquer outra estratégia processual finalizada ao alcance de um acordo. Também naqueles ordenamentos (pensemos à Espanha) que tem mostrado maior sensibilidade normativa frente ao instituto da Mediação, nem todos os problemas de uma sua disposição dogmática encontraram soluções, como demonstra 0 insistente debate sobre a qualificação jurídica do acordo.

E então, tendência à deformação do processo em matéria familiar de um lado, fermentos anárquicos da Mediação de outro, mas, sobretudo emersão do elemento voluntarístico-cooperativo no conseguimento do justo "acordo", conduzem a uma superação da própria aproximação mediativa ou talvez a uma sua transfiguração frente a uma negociação mais generalizada entre as partes, que vêem, precisamente no acordo final mais do que na técnica para alcançá-lo, o momento focal do sistema.

Assim, as formas se multiplicam, o juiz muda veste, os advogados alcançam papéis ulteriores e assim por diante.

Não que isto aconteça sempre e que seja necessariamente uma tendência positiva, sobretudo se o sistema "engole" mais do que metaboliza a mediação e retorna a antigos percursos, deixando sob o plano da apelação cada mudança formal. Como dito, de fato, neste âmbito de relações freqüentemente não entre pares, as modalidades são funções do grau de justiça do acordo alcançado. Mas ao menos esta evolução rompe o grande encanto, a grande ilusão: aquela da cega e talvez maliciosa confiança recolocada em uma técnica assim frágil; a tal ponto precária, que nem mesmo nas mais róseas expectativas resulta em grau de sustentar os problemas da conflitualidade familiar. 


\title{
THE FAMILIARS CONFLICTS AND FAMILIAR MEDIATION IN EUROPE
}

\begin{abstract}
The present article has for objective discuss the family conflicts and the techniques at present utilized in the Europe, more specifically in the Italy, to deter them in an attempt to prevent them or else to treat them, when already in place. In order to meet this goal the paper discusses the availability of the rights in dispute and the possibility that they will be dealt with by mediation, debating the criticisms of such an instrument. Beyond that, the paper of the mediator and of the judge also is aim of inquiry. In these we will have, proposes a reflection about the strategies utilized at present for the resolve the European family conflicts whose model will be able to be absorbed and taken advantage of by the countries of the Latin America, among them Brazil.
\end{abstract}

Keywords: Conflict. Family. Jurisdiction. Mediation.

\section{NOTAS}

1 Tradução de Fabiana Marion Spengler.

2 Professora Ordinaria de Direito Privado Comparado da Università di Salemo onde é responsável cientifica pelo Doutorato de Pesquisa em Comparação e Direito Civil, é também componente do Conselho Diretivo da Escola de Especialização para as Profissões Legais. Leciona, ainda, Instituições de Direito Privado no Campus Link- University of Malta em Roma. Obteve o título de Doutora de pesquisa junto a Università degli Studi di Napoli "Federico II". É autora de numerosos artigos, monografias, comentários e notas menores e dirige os grupos de pesquisa sobre os mais atuais problemas de direito privado italiano e comparado. Atualmente está se ocupando das temáticas que, mais de perto, cuidam do direito de família e das pessoas.

3 "Justice, which is the end of law, is the ideal compromise between the activities of each and the activities of all in a crowded world. The law seeks to harmonize these activities and to adjust therelations of every man with his fellows so as to accord with the moral sense of $f$ the community. When the community is at one in its ideas of justice, this is possible. When the community is divided and diversified, and groups and classes and interests, understanding each other none too well, have conflicting ideas of justice, the task is extremely difficult." (Roscoe Pound) Sobre a relação entre direito e justiça numa perspectiva comparativa, AA.VV., Diritti fondamentali $e$ giustizia civile in Europa, sob os cuidados de M. TARUFFO e V. VARANO, Torino, 2002, passim. Sobre a necessidade de introduzir uma "distinta" maneira de fazer justiça. (CAPPELLETTI, M. Accesso alla giustizia, Milano, 1979, 73; ID, Appunti su conciliatore e conciliazione, in Riv. trim. dir.proc.civ., 1981, 50 ss; contra TARUFFo, ivi, 1990, 349).

4 UlLoA, Modelli di conciliazione nell'esperienza nordamericana, in Riv.trim.dir.proc.civ., 2000, p. 1296.

5 A abertura ao "desenvolvimento de métodos alternativos de resolução de controvérsias" (segundo a terminologia do art. III - 269 , letra g) é, por outro lado, perfil ao qual o próprio Tratado constitucional europeu não deixa de prestar atenção. A escolha a favor de instrumentos de ADR é parte de uma específica estratégia política da União Européia, intimamente ligada à lógica do justo processo. Assim, a nível europeu, foram desenvolvidas algumas estratégias políticas que conduziram o Conselho europeu na reunião de Tampere, de 15 e 16 de outubro, a convidar os Estados membros a instituir procedimentos extrajudiciais e alternativos; a adotar um Livro verde relativo "aos modos alternativos de resolução das controvérsias COM (2002) 196 definitivo, apresentado em Bruxelas em 19 de abril de 2002; à adoção da Diretiva 2008/52/CE do Parlamento europeu e do Conselho de 21 de maio de 2008 "relativa a determinados aspectos da mediação em matéria civil e comercial". Entre as intervenções comunitárias que abrem a técnicas 
de ADR baste recordar, a título meramente exemplificativo, a previsão do art. 17 Diretiva 31/2000, em termos de comércio eletrônico. Sobre o plano do direito interno, a penetração de técnicas de superação do conflito encontra uma aplicação importante em matéria societária, onde a conciliação societária é governada pelo art. 40, decreto legislativo 17 de janeiro de 2003, n. 5 e sucessivas modificações. Sobre a conciliação em matéria societária, (ARIETA-DE SANTIS, Diritto Processuale societário, Padova, 2004, p. 706).

6 Com efeito, as incertezas emergem já sobre o plano da qualificação nos casos concretos de resolução consensual e não decisória dos conflitos. (BIAVATI, Conciliazione strutturata e politiche della giustizia, em Riv. trim. dir.proc. civ., 2005, p. 785).

7 ALPA, Riti alternativi e tecniche di risoluzione stragiudiziale delle controversie in diritto civile, em Politica del diritto, 1997, 403, mas o discurso não pode fazer mais do que apoderar-se também da própria Mediação familiar. Esta se apresenta como uma forma de restabelecimento da ordem violada que, enquanto expressão de atividade conciliativa, encontra aplicação em casos concretos muito diversos. O elemento que torna comuns as diversas figuras deve individuar-se em uma lógica de "governo", do conflito voltado à pesquisa de soluções e de acordos. Mas, se com relação aos objetivos existe concordância em individuar o objetivo último da conciliação-mediação, o dissenso se recupera imediatamente sobre o plano de cada uma das figuras, conforme (MANERA, La mediazione familiare, em Dir.fam., 2004, 815 ss.; PICCARDO, Empowerement, Milano, Raffaello Cortina, 1995, p. 59 ss.; NOREAU \& AMOR, Médiation familiale: de l'experience sociale à la pratique judiciarisée, cit. p. 313 ss.; SUBOURne, Motivations for Mediation: an Examination of the Philosophies Governing Divorce Mediation in the International Context, in Texas International Law Journal, 2003, p. 381 ss).

8 Posicionando-se de modo contrário: CHIARLONI, La conciliazione stragiudiziale come mezzo altemativo di risoluzione delle dispute, em Riv.dir.proc., 1996, 605. Obsenva M. CAPPELLETTI, Dimensioni della giustizia nella società contemporanea, Bologna, 1994, p. 93 ss. que se o risco destas alternativas é aquele de oferecer menores garantias com relação ao juiz; é também verdade que tal limite se supera no momento em que a alternativa não é tornada obrigatória e o controle judicial é sempre garantido; TRUBECK, Les périodes critiques dans l'histoire récente de la théorie de l'accés à la justice: le sujet de droit à la quête de son autonomie, em Annales de Vaucresson, 1988, p. 50 ss. Sobre a oportunidade de uma redefinição das fontes normativas que leve em consideração a complexidade do fenômeno social, P. PERLINGIERI, // diritto civile nella legalità costituzionale, Napoli, 1991, 131, também ID, Diritto comunitario e legalità costítuzionale, Napoli, 1992, p. 17 ss.; T. Ascarelul, Prefazione, in Studi di diritto comparato e in tema di interpretazione, Milano, 1952, XII.

9 CHIARLONI, Stato attuale e prospettive della conciliazione stragiudiziale, in Riv.trim.dir. proc.civ., 2000, p. 455.

10 A Lei 154/2001 introduz no ordenamento um importante instrumento, civilístico e penalístico, que prentende punir o exercício da violência exercitada no âmbito do núcleo familiar. Na doutrina, sobre este aspecto se reenvia, sem todavia nenhuma pretensão de exaustão, à C. MiNNELLA, L'allontanamento dalla casa familiare ex art. 282-bis c.p.p.: problemi e prospettive, in Dir. famiglia 2006, 1, 385; F. AULETTA, Misure (civili) contro la violenza nelle relazioni familiari: ipotesi ricostruttive della I. n. 154 del 2001, em Fam. dir., 2003, 294 ss.; L. A. SCARANO, L'ordine di allontanamento dalla casa familiare, in Familia, 2003, 331 ss.; A. FIGONE, La legge sulla violenza in famiglia, in Fam. e dir., 2001, 355; RANZATTO, Misure a tutela delle vittime delle violenze in famiglia, in Dir. pen. e proc., 2001, 1334; DE MARZO, La legge sulla violenza familiare: uno studio interdisciplinare, in Fam. $e$ dir., 2002, 537; ALLEGRETTO, Le nuove misure cautelari dell'allontanamento dalla casa familiare, in Familia, 2003, 767. A propósito, para a esperienza comparatística, se reenvia ao interessante caso do ordenamento espanhol, C. LASARTE, II diritto di famiglia spagnolo: linee della riforma, in Familia, 2006, 3, 545. Sobre o tema da guarda compartilhada, é vasta a literatura. Se reenvia, por último, sem pretensão de esgotamento, à abrangente análise de SALITO, L'affidamento condiviso, in II diritto di famiglia. Trattato teoricopratico, por obra de Autorino Stanzione, Torino, 2007. Sobre o perfil da mediação, LoNGO, Diritti del minore, mediazione familiare e affidamento condiviso, in Fam. dir., 2003, p. 87.

11 NolAN-HALE, J. M., The Merger of Law and Mediation: Lessons from Equity Jurisprudence and ROSCOE POUND, in Cardozo J. Of Conflict Resolution, 6.57, 2004. p. 64.

12 FULLER, LON. Mediation: Its Forms and Functions, 44 S. C. L. R. 305 325, 1971.

13 M. CAPPELLETTI, Appunti su conciliatore e conciliazione, RTDPC, 1981, p. 49, em condição de dar voz a posições diversamente destinadas a permanecer desconhecidas ( e.g., Penelope E. Bryan, Killing Us Softly: Divorce Mediation and the Politics of Power, p. 40). Não compartilhada aparece, neste sentido, a posição expressa por TARUFFO, Considerazioni sparse su mediazione e diritti, in Annuario di ermeneutica giuridica, 2004, p. 109. Segundo o autor, a proliferação de formas de justiça alternativa seria individuada na 
"conclamada incapacidade do legislador de prever formas rigorosas de tutela jurisdicional dos direitos". Se, na verdade, a ineficiência do sistema contribui para a emersão de instrumentos alternativos de resolução das controvérsias, é também verdade que estes, todavia se colocam para sempre "no sistema", sofrendo (mesmo que por reflexo) as ineficiências do mesmo.

G. MANeRA, La mediazione familiare, in Dir. fam., 2004, 813 ss.; M.L. Missiaggia, Mediazione familiare: una corsa a tappe, in Dir. giust., 2004, n. 42, 106 ss.; BASILE, La mediazione delle controversie sugli effetti della separazione e del divorzio, in Trattato di diritto di famiglia, dir. Zatti, I, Famiglia e matrimonio, t. 2, Milano, 2002, 1484-1485; MNOOKIN \& KORNHAUSER, Bargaining in the Shadow of the law: The Case of Divorce, in Yale Law Journal, 1979, 968, que utilizam a fórmula assaz evocativa, de "bargaining in the shadow of the law"; RONFANI, La déjudiciarisation du contentieux familial, in MEULDERS-KLEIN, Family and justice: Justce civile et évolution du contentieux familial en droit comparé, Paris-Bruxelles, 1997, 45 ss.

Aqui a autora usa o termo "endiade", figura retórica que exprime com dois ou mais termos coordenados (substantivos, adjetivos, verbos) um único conceito. $\mathrm{Na}$ ausência de termo análogo na língua portuguesa, optou-se pela palavra retórica.

17 Sobre a diferença entre formalização e ritualização N. Rouland, Antropologia giuridica, in Giuristi stranieri d'oggi, Milano, 1997, p. 445, que observa como a necessidade do rito seja de entenderse como reafirmação daquele simbolismo do qual qualquer sociedade tem necessidade; ECKOFF, The mediator, the judge and the administrator in conflict resolution, in Acta Sociologica, 1966, p. 172 ss. Uma das críticas avançadas nos confrontos do sistema das ADR é precisamente aquela que se centra sobre o valor e significado de certeza jurídica. Neste sentido, se observou. M. TARUFFo, Aspetti di crisi della giustizia civile: frammentazione e privatizzazione, em Annuario de la Facultad de derecho de la Universitad Autonoma de Madrid, 3 1999, p. 74 que faltaria na ADR 'tanto uma formulação de critérios de valoração e decisão, quanto a possibilidade de qualquer tipo de controle difuso dos órgãos que administram estes métodos. Estes concedem um valor absoluto à decisão ad hoc, embasada na situação específica, sem fazer referência a critérios gerais. Uma conseqüência disto é que muitas soluções são aplicadas seguindo a lógica do "caso a caso", sem que se possa individualizar nenhuma certeza ou ao menos previsão sobre o resultado das controvérsias, nem alguma uniformidade dos critérios para resolvê-las.

18 A propósito, conforme., S. RODOTA', Tecnologia e diritti, Bologna, 1996; E. RESTA, La certezza e la speranza, Bari, 1992; G. ZAGREBELSKY, I/ diritto mite, Torino, 1992. Eficazmente sustentouse a necessidade de "analisar os problemas do condicionamento que a sociedade exerce sobre o processo; do condicionamento que o processo exerce sobre a sociedade e, enfim, da relação entre o estudo do direito e aquele da sociedade, conforme DENTI, Sistematica e post-sistematica nell'evoluzione delle dottrine del processo, em Riv.crit.dir.priv., 1986, p. 480-482; CAPPELLETTI, Dimensione della giustizia, cit., 76. Sobre esse ponto, ainda KENNEDY, Legal Formality, in Joumal of Legal Studies, 1973, p. 360 ss. PERLINGIERI, II diritto civile nella legalità costituzionale, cit., 394 ss.; Id, La personalità umana nell'ordinamento giuridco, Camerino-Napoli, 1972, passim. Mais especificamente em método comparatístico, sobre a necessidade de fazer prevalecer, em sede de divórcio, soluções atentas aos interesses das partes, AUTORINO STANZIONE, Divorzio in diritto comparato, in Dig. disc. priv., Sez. civ., vol. VI, Torino, 1990, p. 499 ss.

19 A diferenciação entre modelos alternativos e jurisdição ordinária é, com efeito, bastante difícil de cumprir, mesmo possuindo na teoria contornos suficientemente bem delineados, conforme ROBERTS, Altermative dispute resolution and civil justice: an unresolved relationship, in Modern Law Rev., 1993, p. 455 ss.; NOREAU, Pluralisme juridique et institutionnalisation des pratiques sociales: le cas de la médiation familiale, em MELKEVIK, Transformation de la culture juridique québécoise, Ste-Foy Press de l'université Laval, 1998, p. 42 ss. Esta aparece destinada a influir sobre o próprio modo de entender o conflito como momento fisiológico mais do que patológico das relações sociais. G. Cosı, Interessi, diritti, potere. Gestione dei conflitti e mediazione, in AA.Vv., Ermeneutica, 23.

20 Veja: FERRANDO, Autonomia privata e mediazione familiare, in Separazione e divorzio, por obra de FERRANDO, Torino, 2003, 549-569; BASILE, La mediazione delle controversie coniugali sugli effetti della separazione e del divorzio, em Tratt. Zatti, I, Famiglia e matrimonio, por obra de FERRANDoFORTINO-RUsCELlo, Milano, 2002, 1483; GIAIMO, La mediazione familiare nei procedimenti di separazione personale e di divorzio. Profili comparatistici, em Dir.fam., 2001, 1606 ss.; DogLIOTTI, La mediazione familiare: un dibattito ancora attuale, em Diritto e famiglia, 1996, 76 ss.; RESCIGNO, Diritto di famiglia e mediazione familiare: il punto di vista del giurista, em La mediazione familiare. Per una regolazione della conflittualità nella separazione e nel divorzio, por obra de Ardone e 
Mazzoni, Milano, 1994, 133 ss. ZAmBRANo, Mediazione e degiuridicizzazione del contenzioso familiare, in Famiglia e diritto:profili evolutivi di un rapporto complesso, Atti del Convegno di Salemo 6-7 ottobre por obra de Zambrano, Quademi del notariato, 2007, passim.

Art. 155 sexies Codice civile italiano: Prima dell'emanazione, anche in via provvisoria, dei provvedimenti di cui all'articolo 155, il giudice può assumere, ad istanza di parte o d'ufficio, mezzi di prova. II giudice dispone, inoltre, l'audizione del figlio minore che abbia compiuto gli anni dodici e anche di età inferiore ove capace di discernimento e deve prendere in considerazione la sua opinione, tenendo conto dell'età e del grado di maturità. II giudice può disporre che il minore sia sentito con audizione protetta, in locali a ciò idonei, anche fuori dell'ufficio giudiziario, e che la medesima, oltre che verbalizzata, sia registrata con mezzi audiovisivi.

22 Art. 768 bis: È patto di famiglia il contratto con cui, compatibilmente con le disposizioni in materia di impresa familiare e nel rispetto delle differenti tipologie societarie, l'imprenditore trasferisce, in tutto o in parte, l'azienda, e il titolare di partecipazioni societarie trasferisce, in tutto o in parte, le proprie quote, ad uno o più discendenti.

23 Art. 342 bis: Ordini di protezione contro gli abusi familiari .Quando la condotta del coniuge o di altro convivente è causa di grave pregiudizio all'integrità fisica o morale ovvero alla libertà dell'altro coniuge o convivente, il giudice, qualora il fatto non costituisca reato perseguibile d'ufficio, su istanza di parte, può adottare con decreto uno o più dei provvedimenti di cui all'articolo 342-ter.
Art.
342
ter:
Contenuto
degli
ordini
di
protezione.

Con il decreto di cui all'articolo 342-bis il giudice ordina al coniuge o convivente, che ha tenuto la condotta pregiudizievole, la cessazione della stessa condotta e dispone l'allontanamento dalla casa familiare del coniuge 0 del convivente che ha tenuto la condotta pregiudizievole prescrivendogli altresì, ove occorra, di non avvicinarsi ai luoghi abitualmente frequentati dall'istante, ed in particolare al luogo di lavoro, al domicilio della famiglia d'origine, ovvero al domicilio di altri prossimi congiunti o di altre persone ed in prossimità dei luoghi di istruzione dei figli della coppia, salvo che questi non debba frequentare i medesimi luoghi per esigenze di lavoro. II giudice può disporre, altresì, ove occorra l'intenvento dei senvizi sociali del territorio o di un centro di mediazione familiare, nonchè delle associazioni che abbiano come fine statutario il sostegno e l'accoglienza di donne e minori o di altri soggetti vittime di abusi e maltrattati; il pagamento periodico di un assegno a favore delle persone conviventi che, per effetto dei provvedimenti di cui al primo comma, rimangono prive di mezzi adeguati, fissando modalità e termini di versamento $e$ prescrivendo, se del caso, che la somma sia versata direttamente all'avente diritto dal datore di lavoro dell'obbligato, detraendola dalla retribuzione allo stesso spettante. Con il medesimo decreto il giudice, nei casi di cui ai precedenti commi, stabilisce la durata dell'ordine di protezione, che decorre dal giorno dell'avvenuta esecuzione dello stesso. Questa non può essere superiore a sei mesi e può essere prorogata, su istanza di parte, soltanto se ricorrano gravi motivi per il tempo strettamente necessario. Con il medesimo decreto il giudice determina le modalità di attuazione. Ove sorgano difficoltà 0 contestazioni in ordine all'esecuzione, lo stesso giudice provvede con decreto ad emanare i provvedimenti più opportuni per l'attuazione, ivi compreso l'ausilio della forza pubblica e dell'ufficiale sanitario.

Obsenva CASTELLO, La mediazione familiare, problemi e prospettive, em Fam.dir., 1994, 681que a incerteza sobre a função do mediador se alimenta da dificuldade de entender se "o mediador se proponha como uma espécie de psicólogo, com o idôneo objetivo de compor os contrastes e conciliar os vários desejos do núcleo familiar, ou se tenda simplesmente a desdramatizar a separação, tornando-a o mais indolor possível MANERA, La mediazione familiare, in Dir.fam., 2004, p. 818 ss.; PETITTI, /I mediatore familiare come ausiliario del giudice, in Fam.dir., 2001, p. 77 ss.

25 Moschella, La mediazione familiare, in Dir.eccl., 2004, p. 350, que não deixa de evidenciar a ausência de uma regra pública de acesso à formação profissional. Nesse contexto se constituíram, a nível europeu, algumas associações como o Forum Europeo - Forum Europeo Formazione e Ricerca em Mediazione familiare (1997) e l'Association pour la Médiation Familial (APMF). Para a experiência italiana vejam-se as referências concluídas por CoLOMBO, $L a$ mediazione familiare, in AA. Vv., Crisi coniugali: riconciliazione e contenzioso giudiziario, Città del Vaticano, 2001, p. 86 ss.

26 Cfr., MoschelLA, La mediazione familiare, cit., p. 353 ss.; MANERA, La mediazione familiare, cit., p. 815 ss.; AA.Vv., La mediazione familiare, a cura del CentroGea, Milano, 1993. Para informações sobre o modo no qual operam as associações de mediadores é possível consultar o site: www.simef.net/simef.html; ou também www.aimef.it. 
Na Gran Bretanha a mediação familiar aparece pela primeira vez no Children Act 1989; e é reconsiderada no Family law Act 1996 e, enfim, no Access to Justice Act 1999. Na Alemanha, onde a Schlichtung tornou-se obrigatória em três Länder, encontra disciplina na lei federal de 15 de dezembro de 1999.

28 Conforme Loi n. 2002-305 du 4 mars 2002, art. 5 que prevê a inserção no código civil do art. 373 2-10 ; Gorchs, La médiation dans le procès civil: sens et contresens, cit., 411; De Munck, De la loi à la mediation, in AA. VV., France: les révolutions invisibiles, Paris, Magnum Photos-Saint Simon, 1998, p. 312. Conforme., l. 21 de janeiro de 2001 (art. 665 do código judiciário belga). ( AMOR, Médiation familiale: de l'experience sociale à la pratique judiciarisée, in Actes Symposium Médiation en Europe: etat des lieux et perspectives, 2004, p. 332. Tribunal de Bari, 21 de novembro 2000, em Fam.dir., 2001, 72 e também na doutrina, PETITTI, /I mediatore familiare come ausiliario del giudice, cit., p. 77 ss. Art. 68, comma 1, Codice procedura civile italiano: 'Nei casi previsti dalla legge, o quando ne sorge necessità, il giudice, il cancelliere o l'ufficilae giudiziario si può fare assistere da esperti in una determinata arte o professione $e$, in generale, da persona idonea la compimento di atti che egli non è in grado di compiere da sé solo.

Dúvidas sobre a oportunidade de tornar obrigatória a conciliação são expressas, de forma mais geral, por CHIARLONI, Brevi note sulla conciliazione stragiudiziale (e contro l'obbligatorietà del tentativo), em Giur. it, 2000 , c. p. 210 ss. UlloA, Modelli di conciliazione, cit., 1289 o qual sublinha como a conexão entre conciliação e eventual ação em juízo apresente não poucos princípios de problematicidade. De particular relevância é a atenção que na Espanha cada um dos Derechos Forales dedicam à mediação, conforme., Castilla y León Ley 1/2006 de 6 abril, in BO. Castilla y León 18 abril 2006, nùm. 75, 2; Canarias, Ley 15/2005; Cataluña Ley 1/2001, de 15 marzo in BOE 16 abril 2001, nùm. 91, 13797; Galicia Ley 4/2001, de 31 mayo, in BOE 2 julio 2001, nùm. 157, 23425; Valencia Ley 7/2001, de 26 noviembre, in DO. Generalitat Valenciana 29 novembre 2001, nùm. 4138, 25105. $\mathrm{Na}$ doutrina, para uma interessante análise do instituto da mediação na Espanha cfr., VıOLA Demestre, La mediación en los conflictos familiares y su eficacia en el ordenamiento jurídico español, em Collantes GonzÁles, Jorge Luis (coord.), Temas Actuales de Derecho civil, Normas Legales, Perù, 2006, p. 521-526.

Tribunal de Bari, 21 de novembro de 2000, em Fam.dir., 2001, 72. Na doutrina, sobre esses perfis: MoschelLA, La mediazione familiare, in Dir.eccl., 2004, p. 350.

37 Precisamente em oposição ao modelo adversarial, de fato, se desenvolvem as técnicas de ADR. Em sentido favorável a esta aproximação, se expressou uma parte da doutrina, especialmente norte americana, conforme., Menkel MEAdow, Pursuing settlement in an adversary culture: a tale of co-opted or the 'Law of ADR', in 19 Fla.St. U.L.Rev., 1991, 1; GoLDBERG-SANDER-ROGERS, Dispute resolution, Boston , 1992, passim. Para uma orientação cética, de acordo com as possibilidades oferecidas a tal modelo alternativo, entre tantos, FISs, Against settlement, in 93 Yale L.J., 1984, 1073; BRUNET, Questioning the quality of alternative dispute resolution, in 62 Tul.L.Rev., 1987, 1 sS; WEINSTEIN, Some benefits and nisks of privatization of justice through ADR, in 11 Ohio St.l. Disp. Res., 1996, 241. Porém, nesta direção, no nosso ordenamento, parecem se mover também as reflexões de TARUFFO, Considerazioni sparse su mediazione $e$ diritti, in Annuario di ermeneutica giuridica, 2004, 110. Por último, por posições mais difusas no que diz respeito ao debate sobre a utilidade do modelo de ADR, RESNICK, Many doors?Closing doors? Altemative dispute resolution and adjudication, in 10 Ohio St.J. Disp. Resol., 1995, p. 212. GaLANTER, Justice in many rooms, in AA.VV., Access to justice, ed. by M. Cappelletti, 1981, 153. Mistelis, ADR in England and Wales, in Am. Rev. Inter., 2001, 168 ss.; ELIS-STUCKLESS, Mediating and Negotiating Marital Conflicts, London, p. 78 ss.

$39 \mathrm{Na}$ Inglaterra numerosos senviços, todos voluntários, afiliados aos Centros Nacionais de Conciliação e Mediação Familiar, aplicam variantes do modelo de mediação estruturada. Essencialmente se pratica a global mediation, seja voluntária seja legal, como aplicação das disposições da Family Law Act (FLA 1996-99). Tais leis, de fato, além da possibilidade de divórcio não fundado sobre a culpa do outro cônjuge, decretam, pela primeira vez, a obrigação, para cada advogado que opere no âmbito do direito de família, de informar aos seus clientes a existência e a fruição da mediação que, deste modo, se torna parte integrante e central do processo de divórcio. Na doutrina GERARD, Family mediation practice in England: wich model, CHILDS GREBE, The structured mediation: an integred model for global mediation in separation and divorce, trad. it. por obra de P. Vitti in Ardone-Mazzoni, op. cit:; Elis-STuckLess, Mediating and Negotiating Marital Conflicts, cit., p. 25 ss. 
Observações críticas sobre a escolha do legislador inglês por não determinar requisitos mínimos de profissionalidade e de disciplinar em concreto a atividade dos mediadores, são expressas por Baronessa Elles, Official Report (H.L.), Jan. 11, 1996, 334; G. GIAIMO, La mediazione familiare nei procedimenti di separazione personale e di divorzio. profili comparatistici, in Dir. famiglia, 2001, 4, 1615. Para a experiência estadunidense, conforme PEARSOn AND ThOENnES, Divorce Mediation: An American Picture, in Dingwall and Eekelaar, Divorce Mediations and the Legal Process, cit., 72; e também a análise feminista sobre os resultados da mediação, em temos de estratégia político-social efetuada por GIRDNER, Custody mediation in the United States: Empowerment or Social Contror?, em Can. Jour. of Woman and Law, 1989, p.135 ss.

41 Conforme, na doutrina, para uma interessante análise do instituto da mediação na Espanha, conforme VIOLA DEMESTRE, La mediación en los conflictos familiares y su eficacia en el ordenamiento jurídico español, em ColLANTES GonZÁlES, Jorge Luis (coord.), Temas Actuales, cit., p. 516-517. A autora observa como a mediação, no sistema espanhol se configure como um processo extrajudicial de resolução de conflitos. Ele se realiza sob a base voluntária e confidencial, na qual uma terceira pessoa, imparcial, cria um espaço de diálogo a fim de que as partes em conflito possam se comunicar entre elas, manifestando as próprias expectativas, interesses, necessidades. O objetivo é, em outros termos, aquele de alcançar um acordo duradouro e que satisfaça ambas as partes.

Conforme, Bernal SAMPER, La Mediaciòn. Una soluciòn a los conflictos de pareja, Madrid, 1998; II "Servei de Mediaciò Familar de Barcelona" dipende dall' "Institut de Treball Social i Servesi Socials" (INTRESS), criado em 1992, VID. RIPOL-MILLET, Separaciò i divorci: ma Mediaciò familiar, Generalitat de Catalunya. Département de Justicia, 1995. Os Institutos de Psicologia Juńdica de Madrid e Barcellona, por outro lado, foram pioneiros em demonstrar as inter-relações entre direito e psicologia, sobretudo no campo familiar. Para aprofundamentos, sobre o ponto, M. LUISA JORDAN VILLACAMPA, La mediaciòn familiar: recurso volontario u obbligatorio, em Dir. Ecclesiastico, 1999, passim.

ALPA, Riti alternativi e tecniche di risoluzione stragiudiziale delle controversie in diritto civile, em Politica del diritto, 1997, p. 433.

44 Pela existência de uma real e recíproca coordenação entre settlement e adjudication, EMERY, Divorce Mediation in the USA, em Int. Fam.Law J., 2005, p. 64. Sobre o tema, ChIARLONI, La conciliazione stragiudiziale, cit., 694; ULLOA, Modelli di conciliazione, cit., p. 1290.

46 Semelhante "ideal", de fato, aparece destinado a romper-se contra uma dimensão processual da justiça que individualiza na sentença o êxito fisiológico da controvérsia (Principles of Family Law, VII ed., S.M. CRETNEY- J.M. MASON-R. BAILEY-HARRIS, London, 2003, 307).

47 De um ponto de vista sociológico, a Mediação se alimenta das transformações sofridas pela família, também em consideração das reformas em matéria de divórcio e do progressivo desaparecimento da noção de culpa, NOREAU \& AMOR, Médiation familiale: de l'experience sociale à la pratique judiciarisée, em Actes Symposium Médiation en Europe: etat des lieux et perspectives, 2004, 312; PEARson, A Forum for Every Fuss: the Growth of Court Services and ADR Treatment for Family Law Cases in the United States, in KARZ, EEKELAAR and MACLEAN, Cross Currents. Family Law and Policy in the United States and England, Oxford University Pres, 2000,513 ss. A mediação na teoria se propõe a favorecer "a reabertura dos processos comunicativos e relacionais, sobretudo nos casos de separação e divórcio" superando, precisamente, o perfil da culpa, conforme, MANERA, La mediazione familiare, cit., p. 817 ss.

48 A respeito da diminuição da tutela ofertada aos cidadãos, discorrem, na verdade, aqueles autores que desenvolveram uma aproximação crítica frente às formas de justiça informal conforme FISs, Against settlement, cit, 1073; BRUNET, Questioning the quality of alternative dispute resolution, cit., 4 ss; WeINSTEIn, Some benefits, cit., p. 242 ss.

49 A exigência de evitar que o recurso à mediação se resolva em um instrumento de pressão psicológica sobre a mulher, é perfil sobre o qual o feminismo juńdico não deixa de discutir, conforme EdWARd Patricial, Gender Issues in Family Law: A Feminist Perspective, in Family and Conciliation Courts Review, vol. 35, 424-442; GRILLO, The Mediation Alternative: Process Dangers for Women, 100 (1991) Yale Law Journal, 1545-1610; SHAFFER, Divorce mediation: a feminist perspective, em Faculty Law Review, Toromto, 1988, 168 ss. Neste sentido, além dele TARUfFO, Considerazioni sparse su mediazione e diritti, em Annuario di emmeneutica giuridica, 2004, 110 que observa como também no processo de mediação deveria ser garantida, de qualquer forma, uma "substancial igualdade de tratamento processual" às partes. 
Conforme, BICKERDIKE.LITTLEFIELD, Divorce Adjustement and Mediation. Theoretically grounded Process Research, 18 Mediation Quaterly, 2000, 181 cuja análise evidencia, exatamente, as interrelações entre processo, conduta do mediador e interação das partes.

CRAIG MC EWEN, Bring in the lawyers: challenging the dominant approaches to ensuring fariness in divorce mediation, 79 (1995) Minn. L.Rev. p. 1317. comparatistici, cit., p. 1606. MANERA, La mediazione familiare, in Dir.fam., 2004, p. 815 ss.

$\mathrm{Na}$ jurisprudência, sobre a aplicação do art. 1322 c.c., e mais em geral sobre o crescente espaço atribuído à autonomia dos cônjuges, entre tantos, Cass. civ., 23 luglio 1987, n. 6424, em Giust.civ., 1988, I, 459; Cass.civ., 21 dicembre 1987, n. 9500, in Riv.dir.civ., 1989, II, 233; Cass.civ., 17 giugno 1992, n. 7470, em Nuova giur.civ.comm., 1993, I, 808; Cass.civ., 22 gennaio 1994, n. 657; Cass.civ., 28 luglio 1997, n. 7029, em Mass. Giur.it, 1997, 177; Cass.civ., sez. II, 21 febbraio 2006, n. 3747, em Giust. civ. Mass., 2006, 9. Sobre esses perfis, na doutrina, vejam-se as reflexões comparativas de MARELLA, Gli accordi fra coniugi fra suggestioni comparatistiche $e$ diritto interno, in AA.Vv., Separazione e divorzio, por obra de Ferrando, Torino, 2003, p. 194 ss. NOREAU, Familles séparées et rupture du droit. Du mélange des genres familiaux à la redéfinition du droit de la famille, in Actes Symposium Médiation en europe: etat des lieux et perspectives, 2004.

Conforme Cfr., BonAfE-SCHMITT, La médiation: une alternative à la justice?, em KASIREE ET NOREAU, Sources et instruments de justice en droit privé, Montréal, Thémis, 144 ss.; NOREAU \& AMOR, Médiation familiale: de l'experience sociale à la pratique judiciarisée, cit., p. 312 ss.

BUTRUILLE-CARDEW, Le droit de famille collaborative (Collaborative Law), em Famille. Actualité Juridique, 2007, 29 ss.; TESLER, Collaborative Law: What It Is and Why Family Law Attomey Need to Know About It, em Am.J.Family Law, 1999, p. 225.

58 MenKEL-MeAdow, The Many Ways of Mediation: the Transformation of Tradition, Ideolgies, Paradigms and Practice, in Menkel- MeAdow, Mediation, Theory, Policy and Practice, Aldershot (England), Ashgate Publishing Limited, 2001, p. 120 ss.

59 M. GLEASER-K. BLAISURE, $A$ review of divorce education program materials, 47 Family Relations 23 (1998); J. PEARSON, A forum for every fuss: the growth of court service and ADR treatments for family law cases in the USA, em AA.VV., Cross current. Family law and policy in the USA and England, N. KATZ, J. Eeckelaar and M. Maclean (ed.), Oxford, 2000, p. 518 ss.

60 A classificação do modelo de "tratativa assistida", como modelo de resolução de controvérsias, segue coordenadas bastante articuladas. Elas são reconduzidas a perfis de a) norm generating quando se esteja na presença de uma rejeição das regras próprias da adjudication, b) norm educating, nas quais o acordo é alcançado em um quadro normativo de referência, por meio do qual as partes são colocadas em grau de conhecer as potencialidades, onde efetuar escolhas adequadas; c) norm advocating, na qual o acordo é alcançado respeitando as normas de lei, de cuja aplicação por obra das partes o terceiro se preocupa, ULLOA, Modelli di conciliazione, cit., 1300 ss. Neste sentido, a mediação familiar, próprio na originalidade da aproximação que solicita, pareceria apresentar-se, mais do que outro, como um modelo norm educating.

\section{REFERÊNCIAS}

ALLEGRETTO. Le nuove misure cautelari dell'allontanamento dalla casa familiare, Familia, 2003.

ALPA. Riti alternativi e tecniche di risoluzione stragiudiziale delle controversie in diritto civile. Politica del diritto, 1997.

ARIETA; DE SANTIS. Diritto Processuale societário. Padova: [s.n.], 2004.

ASCARELLI, T. Prefazione, Studi di diritto comparato e in tema di interpretazione, Milano, 1952. 
AULETTA, F. Misure (civili) contro la violenza nelle relazioni familiari: ipotesi ricostruttive della I. n. 154 del 2001, Fam. dir., 2003.

AUTORINO STANZIONE. Divorzio in diritto comparato, Dig. disc. prív., Sez. cív., Torino, v. 6, 1990.

BASILE. La mediazione delle controversie coniugali sugli effetti della separazione e del divorzio. In: FERRANDO; FORTINO; RUSCELLO. Famiglia e matrimonio. Tratt. Zatti, I. Milano: [s.n.], 2002.

BERNAL SAMPER. La Mediaciòn. Una soluciòn a los conflictos de pareja. Madrid, 1998.

BIAVATI. Conciliazione strutturata e politiche della giustizia, Riv. trim. dir. proc. civ., 2005.

BICKERDIKE; LITTLEFIELD. Divorce Adjustement and Mediation. Theoretically grounded Process Research, Mediation Quaterly, 18, 2000.

BONAFÉ-SCHMITT. La médiation: une alternative à la justice?. In: KASIRÉE ET NOREAU. Sources et instruments de justice en droit privé. MONTRÉAL: Thémis.

BRUNET, Questioning the quality of altemative dispute resolution, Tul.L.Rev., 62, 1987.

BRYAN, Penelope E. Killing Us Softly: Divorce Mediation and the Politics of Power, [S.I.:S.n.].

BUTRUILLE-CARDEW. Le droit de famille collaborative (Collaborative Law), Famille. Actualité Juridique, 2007.

CAPPELLETTI, M. Appunti su conciliatore e conciliazione, RTDPC, 1981.

CAPPELLETTI, M. Dimensioni della giustizia nella società contemporanea. Bologna: [s.n.], 1994.

. Accesso alla giustizia. Milano: [s.n.], 1979.

. Appunti su conciliatore e conciliazione, Riv. trim. dir. proc. civ., 1981.

. Dimensione della giustizia. [S.I.: s.n.]

Cass. civ., 23 luglio 1987, Giust. civ., n. 6424, I, 1988.

Cass.civ., 17 giugno 1992, Nuova giur.civ.comm., n. 7470, I, 1993.

Cass.civ., 21 dicembre 1987, Riv.dir.civ., n. 9500, II, 1989.

Cass.civ., 28 luglio 1997, Mass. Giur.it., n. 7029, 1997. 
Cass.civ., sez. II, 21 febbraio 2006, Giust. civ. Mass., n. 3747, 2006.

CASTELLO. La mediazione familiare, problemi e prospettive, Fam. dir., 1994.

CHIARLONI. Brevi note sulla conciliazione stragiudiziale (e contro l'obbligatorietà del tentativo), Giur. it, 2000.

. La conciliazione stragiudiziale come mezzo alternativo di risoluzione delle dispute, Riv. dir. proc., 1996.

. Stato attuale e prospettive della conciliazione stragiudiziale, Riv. trim. dir. proc. Civ., 2000.

CHILDS GREBE. The structured mediation: an integred model for global mediation in separation and divorce. Trad. it. por obra de P. Vitti. In: ARDONE; MAZZONI. (Org.). La mediazione familiare. Per una regolazione della conflittualità nella separazione $e$ nel divorzio. Milano: [s.n.], 1994.

COLOMBO. La mediazione familiare, AA. VV., Crisi coniugali: riconciliazione e contenzioso giudiziario, Città del Vaticano, 2001.

COSI, G. Interessi, diritti, potere. Gestione dei conflitti e mediazione, AA.VV., Ermeneutica.

CRETNEY, S.M.; MASON, J.M.; BAILEY, R.; HARRIS. Principles of Family Law. 7. ed. London: [s.n.], 2003.

DE MARZO. La legge sulla violenza familiare: uno studio interdisciplinare, Fam. $e$ dir., 2002.

DE MUNCK. De la loi à la mediation, AA. VV., France: les révolutions invisibiles, Paris: Magnum Photos-Saint Simon, 1998.

DENTI. Sistematica e post-sistematica nell'evoluzione delle dottrine del processo, Riv. crit. dir. priv., 1986.

DOGLIOTTI. La mediazione familiare: un dibattito ancora attuale, Diritto e famiglia, 1996.

ECKOFF. The mediator, the judge and the administrator in conflict resolution, Acta Sociologica, 1966.

EDWARD PATRICIAL. Gender Issues in Family Law: A Feminist Perspective, in Family and Conciliation Courts Review, v. 35, 1991.

ELIS; STUCKLESS. Mediating and Negotiating Marital Conflicts. London: [s.n.].

ELLES, Baronessa. Official Report (H.L.), Jan. 11, 1996.

EMERY. Divorce Mediation in the USA, Int. Fam. Law J., 2005. 
FERRANDO. Autonomia privata e mediazione familiare. In: . (Org.).

Separazione e divorzio. Torino: [s.n.], 2003.

FIGONE, A. La legge sulla violenza in famiglia, Fam. e dir., 2001.

FISS. Against settlement, Yale L.J., 93, 1984.

FULLER, LON. Mediation: Its Forms and Functions, S. C. L. R., 44, 1971.

GALANTER. Justice in many rooms. In: CAPPELLETTI, M. AA.VV., Access to justice. [S.I.:S.n.], 1981.

GERARD. Family mediation practice in England: wich model.

GIAIMO, G. La mediazione familiare nei procedimenti di separazione personale e di divorzio. profili comparatistici, Dir. famiglia, 4, 2001.

GIRDNER. Custody mediation in the United States: Empowerment or Social Control?, Can. Jour. of Woman and Law, 1989.

GOLDBERG; SANDER; ROGERS. Dispute resolution. Boston, [s.n.], 1992.

GORCHS. La médiation dans le procès civil: sens et contresens, cit.,

GRILLO. The Mediation Altemative: Process Dangers for Women, Yale Law Journal, 100, 1991.

JORDAN VILLACAMPA, M. LUISA. La mediaciòn familiar: recurso volontario u obbligatorio, Dir. Ecclesiastico, 1999.

KENNEDY. Legal Formality, Journal of Legal Studies, 1973.

LASARTE, C. Il diritto di famiglia spagnolo: linee della riforma, Familia, 3, 2006.

LONGO, F. Diritti del minore, mediazione familiare e affidamento condiviso, Fam. dir., 2003.

M. GLEASER; K. BLAISURE. A review of divorce education program materials, Family Relations, 47, 1998.

MANERA, G. La mediazione familiare, Dir. fam., 2004.

MANERA. La mediazione familiare. Dir. fam., 2004.

MARELLA. Gli accordi fra coniugi fra suggestioni comparatistiche e diritto interno. In: FERRANDO. (Org.). AA.VV., Separazione e divorzio. Torino: [s.n.], 2003.

MC EWEN, Craig. Bring in the lawyers: challenging the dominant approaches to ensuring fariness in divorce mediation, Minn. L.Rev, 79, 1995. 
MENKEL MEADOW. Pursuing settlement in an adversary culture: a tale of co-opted or the 'Law of ADR", Fla.St. U.L.Rev., 19, 1991.

MENKEL-MEADOW. The Many Ways of Mediation: the Transformation of Tradition, Ideolgies, Paradigms and Practice. In: . Mediation, Theory, Policy and Practice. Aldershot (England): Ashgate Publishing Limited, 2001.

MINNELLA, C. L'allontanamento dalla casa familiare ex art. 282-bis c.p.p.: problemi e prospettive, Dir. famiglia, 1, 2006.

MISSIAGGIA, M.L. Mediazione familiare: una corsa a tappe, Dir. giust., n. 42, 2004.

MISTELIS. ADR in England and Wales, Am. Rev. Inter., 2001.

MNOOKIN; KORNHAUSER. Bargaining in the Shadow of the law: The Case of Divorce, Yale Law Journal, 1979.

MOSCHELLA. La mediazione familiare, Dir. eccl., 2004.

NOLAN, J. M.; HALE, The Merger of Law and Mediation: Lessons from Equity Jurisprudence and ROSCOE POUND. In: CARDOZO, J. Of Conflict Resolution, 6.57, 2004.

NOREAU. Familles séparées et rupture du droit. Du mélange des genres familiaux à la redéfinition du droit de la famille, Actes Symposium Médiation en europe: etat des lieux et perspectives, 2004.

. Pluralisme juridique et institutionnalisation des pratiques sociales: le cas de la médiation familiale. In: MELKEVIK. Transformation de la culture juridique québécoise. [S.I.]:Ste-Foy Press de l'université Laval, 1998.

; AMOR. Médiation familiale: de l'experience sociale à la pratique judiciarisée, Actes Symposium Médiation en Europe: etat des lieux et perspectives, 2004.

PEARSON. A Forum for Every Fuss: the Growth of Court Services and ADR Treatment for Family Law Cases in the United States. In: KARZ; EEKELAAR; MACLEAN. Cross Currents. Family Law and Policy in the United States and England. Oxford: Oxford University Pres, 2000.

PERLINGIERI, P. Diritto comunitario e legalità costituzionale, Napoli: [s.n.], 1992.

. I/ diritto civile nella legalità costituzionale. Napoli: [s.n.], 1991.

PETITTI. II mediatore familiare come ausiliario del giudice, Fam. dir., 2001.

PICCARDO. Empowerement Milano: Raffaello Cortina, 1995.

RANZATTO. Misure a tutela delle vittime delle violenze in famiglia, Dir. pen. e proc., 2001. 
RESCIGNO. Diritto di famiglia e mediazione familiare: il punto di vista del giurista. In: ARDONE; MAZZONI. (Org.). La mediazione familiare. Per una regolazione della conflittualità nella separazione e nel divorzio. Milano: [s.n.], 1994.

RESNICK. Many doors?Closing doors? Alternative dispute resolution and adjudication, Ohio St.J. Disp. Resol., 10, 1995.

RESTA, E. La certezza e la speranza. Bari: [s.n.], 1992.

RIPOL, VID.; MILLET. Separaciò i divorci: ma Mediaciò familiar. Generalitat de Catalunya: Département de Justìcia, 1995.

ROBERTS. Alternative dispute resolution and civil justice: an unresolved relationship, Modern Law Rev., 1993.

RODOTA, S. Tecnologia e diritti. Bologna: [s.n.], 1996.

RONFANI. La déjudiciarisation du contentieux familial. In: MEULDERS; KLEIN. Family and justice: Justce civile et évolution du contentieux familial en droit comparé. Paris-Bruxelles: [s.n.], 1997.

ROULAND, N. Antropologia giuridica, Giuristi stranieri d’oggi, Milano, 1997.

SALITO. L'affidamento condiviso, // diritto di famiglia. Trattato teorico-pratico, por obra de Autorino Stanzione. Torino, 2007.

SCARANO, L. A. L'ordine di allontanamento dalla casa familiare, Familia, 2003.

SHAFFER. Divorce mediation: a feminist perspective, Faculty Law Review, Torornto, 1988.

SUBOURNE. Motivations for Mediation: an Examination of the Philosophies Governing Divorce Mediation in the International Context, Texas International Law Journal, 2003.

TARUFFO, M. Aspetti di crisi della giustizia civile: frammentazione e privatizzazione, Annuario de la Facultad de derecho de la Universitad Autonoma de Madrid, 3, 1999. giuridica, 2004.

Considerazioni sparse su mediazione e diritti, Annuario di ermeneutica

TESLER. Collaborative Law: What It Is and Why Family Law Attorney Need to Know About It, Am. J. Family Law, 1999.

TRUBECK. Les périodes critiques dans l'histoire récente de la théorie de l'accés à la justice: le sujet de droit à la quête de son autonomie, Annales de Vaucresson, 1988.

ULLOA. Modelli di conciliazione nell'esperienza nordamericana, Riv. trim. dir. proc. civ., 2000. 
VIOLA DEMESTRE. La mediación en los conflictos familiares y su eficacia en el ordenamiento jurídico español. In: COLLANTES GONZÁLES, Jorge Luis (Org.). Temas Actuales de Derecho civil. Normas Legales. Perù: [s.n.], 2006.

WEINSTEIN. Some benefits and riisks of privatization of justice through ADR, Ohio St.I. Disp. Res., 11, 1996.

ZAGREBELSKY, G. // diritto mite. Torino: [s.n.], 1992.

ZAMBRANO. Mediazione e degiuridicizzazione del contenzioso familiare, Famiglia $e$ diritto:profili evolutivi di un rapporto complesso, Atti del Convegno di Salerno 6-7 ottobre por obra de Zambrano, Quaderni del notariato, 2007.

Recebido para publicação 11/12/2009

Aceito para publicação 30/12/2009 